\title{
Effects of glucagon on resting and exercise haemodynamics in patients with coronary heart disease
}

\author{
Burton H. Greenberg, Ben D. McCallister, and Robert L. Frye \\ From the Mayo Clinic and Mayo Foundation, Rochester, Minnesota, U.S.A.
}

The haemodynamic effects of glucagon administered into the pulmonary artery in a single dose of 15, 30, or $45 \mu \mathrm{g} / \mathrm{kg}$ were studied in 9 patients who had coronary heart disease. Glucagon did not significantly affect heart rate, cardiac index, left ventricular end-diastolic pressure, or mean brachial artery pressure either at rest or during mild supine leg exercise. The abnormal increase in left ventricular end-diastolic pressure seen in some patients during exercise was not prevented by glucagon administration. A second group of patients underwent two identical periods of exercise separated by a Io-minute period of rest. The changes in the haemodynamic parameters measured were reproducible between exercise periods.

Glucagon has been reported to have significant inotropic effects in various animal preparations (Farah and Tuttle, 1960; Glick et al., 1968; Regan et al., 1964) and in normal subjects or cardiac patients in functional classes $I$ and 2 (Klein, Morch, and Mahon, 1968; Linhart et al., 1968; Parmley, Glick, and Sonnenblick, 1968). It has been less effective in patients with various myocardial diseases in functional class 3 or 4 (Williams et al., 1969) and after aortic or mitral (or both) valve replacement (Sonnenblick, Parmley, and Matloff, I968). Glucagon has had no significant haemodynamic effect in patients with rheumatic heart disease in chronic congestive heart failure (Greenberg et al., 1970) or in the presence of cardiogenic shock (Gregory et al., 1969). To elucidate further the potential clinical value of glucagon, the present study was designed to evaluate, at rest and after mild supine leg exercise, the haemodynamic effects of glucagon in patients with coronary heart disease.

\section{Subjects and methods}

Eighteen patients (17 men and I woman), who had severe angina pectoris, were studied at the time of selective coronary arteriography as possible candidates for coronary arterial surgery. The ages of the patients ranged from 35 to $\mathbf{6 2}$ years, with a mean of 49 years. All patients were informed of the investigative and elective nature of the study. All patients had angiographic evi-

Received 17 January 1972. dence of significant coronary artery disease. None had symptoms of congestive heart failure, and none had cardiomegaly. The studies were performed in the fasting state, after premedication with $100 \mathrm{mg}$ pentobarbitone, and before injection of contrast material. Mean brachial artery pressure, heart rate, cardiac index by the indicatordilution technique, and left ventricular end-diastolic pressure were determined at rest with the patient's feet raised in a bicycle ergometer for 5 minutes and after 3 minutes of supine leg exercise at $100 \mathrm{~kg} \mathrm{~m} / \mathrm{min}$. All patients were then rested for Io minutes, after which haemodynamic parameters were again measured. Glucagon ${ }^{1}$ was then injected into the main pulmonary artery of 9 patients. In order to investigate a possible relation between dose and haemodynamic response, a single dose of 15,30 , or $45 \mu \mathrm{g} / \mathrm{kg}$ was used. The average individual dose of glucagon was $2.3 \mathrm{mg}$, with a range of from $\mathrm{r} \cdot 0$ to $3.6 \mathrm{mg}$. Higher dose levels were not investigated because nausea occurred in patients who received $45 \mu \mathrm{g} / \mathrm{kg}$. The same haemodynamic parameters were then measured to minutes after the administration of glucagon and after an identical 3 minutes of supine leg exercise. In order to determine the reproducibility of the haemodynamic changes, the remaining 9 patients underwent a second identical period of exercise after the 10-minute rest, without the administration of glucagon.

\section{Results}

There were no differences between the untreated group and the group treated with glu-

${ }^{1}$ Kindly supplied by Eli Lilly and Company, Indianapolis. 
cagon in age, clinical status, and coronary arteriographic findings. Similarly, there were no differences between the groups in the mean - values for each of the haemodynamic parameters measured either at rest or during $s$ exercise.

Reproducibility of exercise haemodynamics The haemodynamic parameters in the 9 patients who underwent two identical periods of supine leg exercise without any intervention are shown in Table I. Comparison of the initial measurements at rest with those ro minutes after the first exercise period revealed no significant difference in the mean values for heart rate, cardiac index, left ventricular end-diastolic pressure, and mean brachial artery pressure. There were also no significant differences in mean values for these parameters when the two exercise periods were compared. These parameters varied only slightly between respective rest and exercise periods for individual patients (Fig. I to 4 ). Five of the 9 patients had increases in left ventricular end-diastolic pressure that were

A greater than $23 \mathrm{mmHg}$ during the first exercise period, with increases of $8,14,18,19$,

and 27, respectively, as compared with increases in the second exercise period of 3,8 , 14, I3, and $24 \mathrm{mmHg}$.

Effects of glucagon on resting haemoa dynamics The effects of glucagon on the haemodynamic parameters at rest in 9 patients are shown in Table 2. There was no significant change in the mean value for all patients in each of the haemodynamic parameters measured Io minutes after glucagon administration (Fig. 5). Increasing the doses of glucagon had no apparent effect on the magnitude of response for each of the haemodynamic parameters measured. Two patients had increases in cardiac index of 10 to 14 per cent, and only one patient had a more substantial increase of 33 per cent, as compared with that before glucagon administration. Only one patient had an increase in heart rate ( 8 beats $/ \mathrm{min}$ ).

The effects of glucagon on exercise haemodynamics The effects of glucagon on the haemodynamic parameters during exercise are shown in Table 2. The average values for all patients for each of the haemodynamic parameters measured were almost identical during the two rest periods and again during exercise, despite glucagon administration. There was little variation among patients in respective rest and exercise periods (Fig. I to 4). The cardiac indices were higher during the second exercise period in only two patients ( 0.8 to $0.91 . / \mathrm{min} / \mathrm{m}^{2}$ ). Four patients each had an abnormal increase in left ventricular end-diastolic pressure during the first exercise period, and glucagon administration did not present this abnormal response during the

TABLE I Haemodynamic parameters at rest and during exercise in patients with coronary heart disease who did not receive glucagon

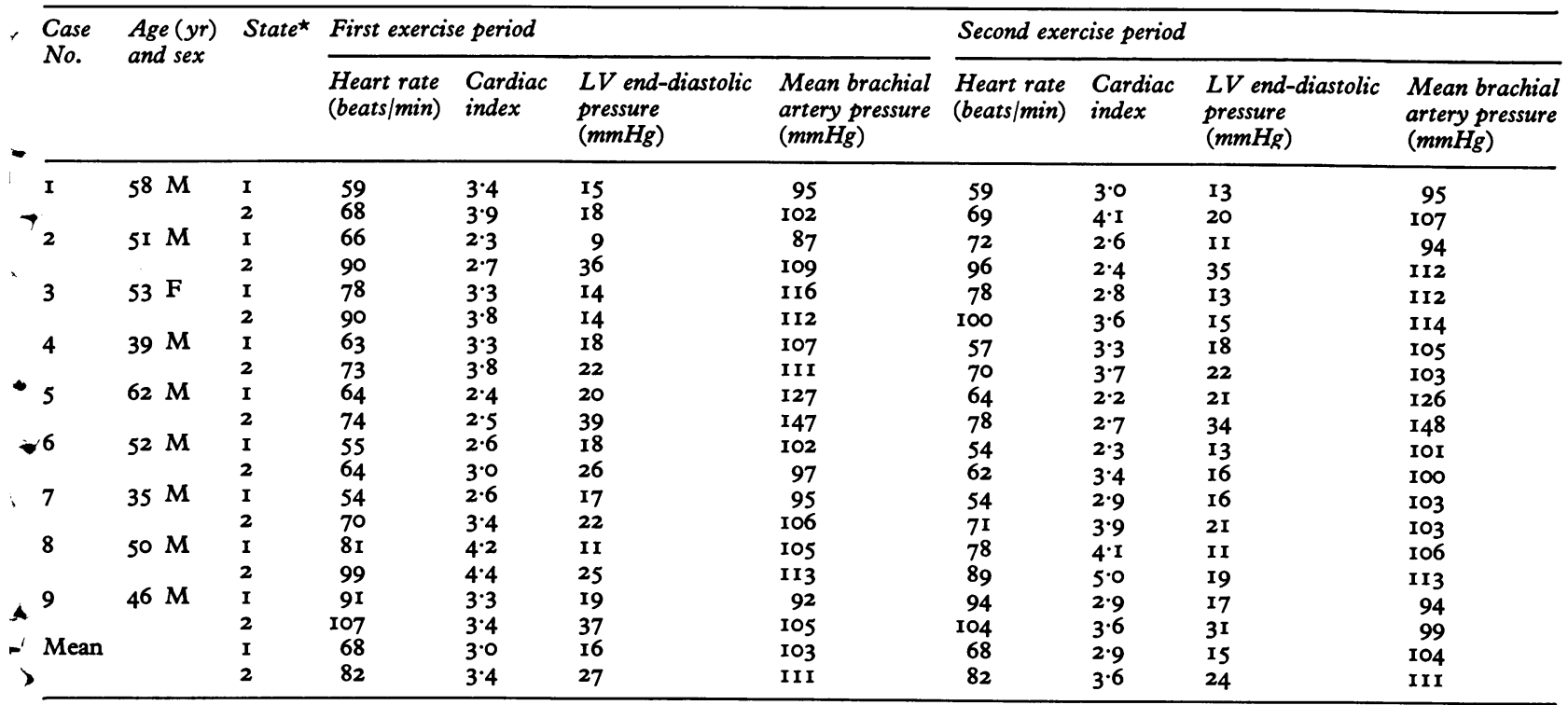

* $I=$ immediately before exercise; $2=$ after 3 minutes of exercise. 
second period of exercise. An additional patient had an abnormal increase in left ventricular end-diastolic pressure only during the second exercise period and after he had received glucagon.

\section{Discussion}

Previously, we have reported that little or no change occurred in heart rate, cardiac index, left ventricular end-diastolic pressure, and mean femoral artery pressure after the administration of glucagon to a group of patients with valvular heart disease in chronic congestive heart failure (Greenberg et al., 1970). In the present study, no significant change in these haemodynamic parameters was observed after glucagon use in patients with coronary heart disease, either at rest or during mild supine leg exercise. Similar findings also have been noted in patients with hypertensive or primary myocardial disease (Williams et al., 1969) and in cardiogenic shock (Gregory et al., 1969). These results are in contrast with the significant increases in cardiac index observed in most cardiac patients in functional class I or 2 after glucagon administration, as reported by several investigators (Klein et al., 1968; Linhart et al., 1968; Parmley et al., 1968). The most obvious explanation for the difference in response is the smaller dose of glucagon used in the present study. It should then be emphasized that the present results were obtained without induction of nausea, but that more impressive inotropic effects might be observed with larger doses of glucagon. It did not seem justified in the present study to use larger doses and risk induction of nausea and vomiting as further diagnostic studies were required. Furthermore, interpretation of the haemodynamic data would be difficult in the presence of increased autonomic activity associated with the nausea and vomiting known to occur in some patients with larger doses of glucagon. It is difficult to compare, with confidence, patients in the present study, none of whom had clinical congestive heart failure, with those of previous studies who had frank congestive heart failure. However, recent studies by others (Gold et al., 1970) of the effect of chronic heart failure on the activation of adenyl cyclase by glucagon are of importance in explaining differences in response

FIG. 3 Effects of glucagon on left ventricular end-diastolic pressure of patient with coronary heart disease. Left panel: during two rest periods. Right panel: during two exercise periods.
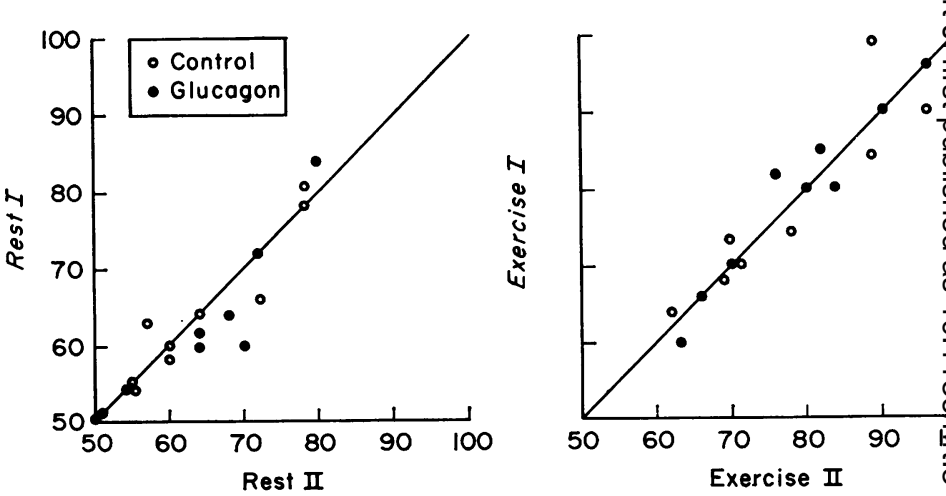

Heart rate (beats / $\mathrm{min}$ )

FIG. I Effects of glucagon on heart rate of patients with coronary heart disease. Left panel: during two rest periods. Right panel: during two exercise periods.

FIG. 2 Effects of glucagon on cardiac index of patient with coronary heart disease. Left panel: during two rest periods. Right panel: during two exercise periods.
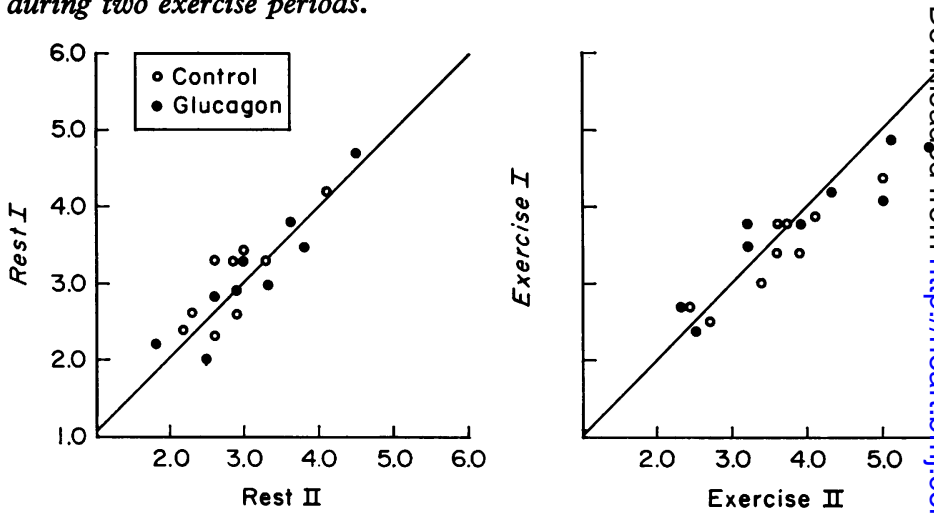

Cardiac index $\left(L / \mathrm{min} / \mathrm{M}^{2}\right)$
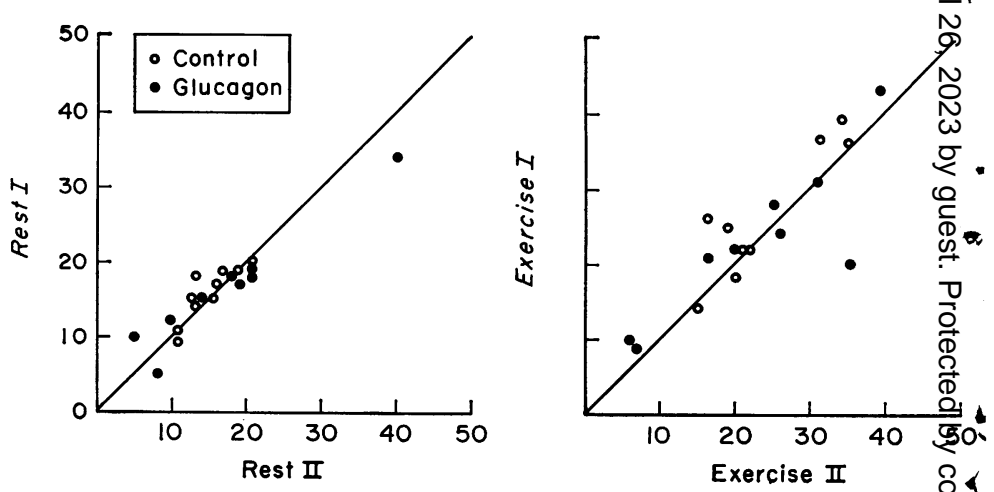

$\operatorname{LVEDP}(\mathrm{mm} \mathrm{Hg})$ 
of patients. It was shown that chronic right heart failure induced in cats by banding the pulmonary artery severely reduced or abolished the positive inotropic effects of glucagon.

- However, acute heart failure induced by pulmonary artery banding did not result in a reduction of the inotropic action of glucagon. These findings of reduced inotropic activity of glucagon in the animals with chronic heart failure were associated with a reduced capacity of glucagon to activate adenyl cyclase.

- The haemodynamic effects of repeated exercise have been evaluated in studies of patients in the supine (Malmborg, 1965; Widimsky, Berglund, and Malmberg, 1963) and the erect positions (Burkart, Barold, and Sowton, 1967; Epstein et al., I965). Because of differences in experimental design,

1 these studies are not directly comparable, though certain directional changes were noted. in general, differences between identical periods of exercise, when present, were greatest at the outset of exercise, at high work
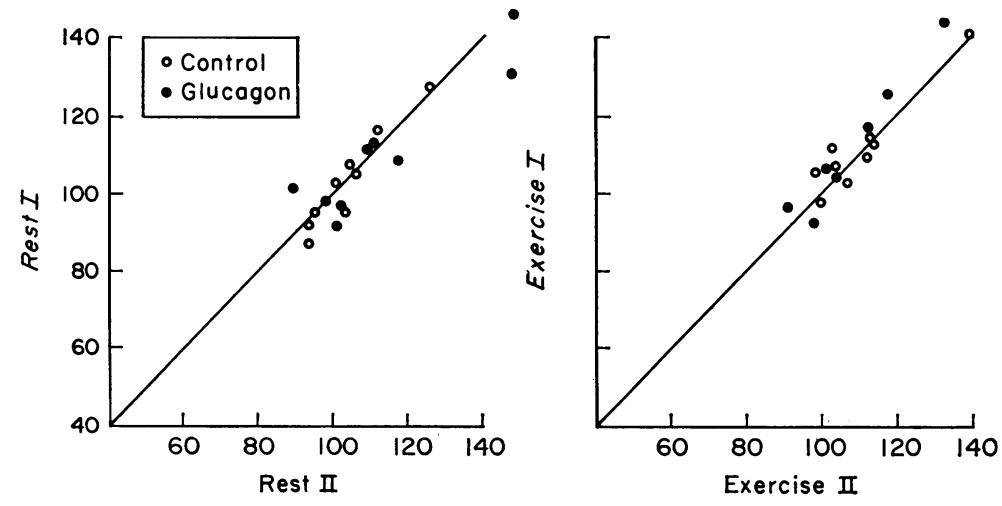

$\overline{\mathrm{BAP}}(\mathrm{mmHg})$

FIG. 4 Effects of glucagon on mean brachial artery pressure of patients with coronary heart disease. Left panel: during two rest periods.

Right panel: during two exercise periods.

TABLE 2 Haemodynamic parameters at rest and during exercise in patients with coronary heart disease who received glucagon

\begin{tabular}{|c|c|c|c|c|c|c|c|c|c|c|c|c|}
\hline \multirow{2}{*}{$\begin{array}{l}\text { Case } \\
\text { No. }\end{array}$} & \multirow{2}{*}{$\begin{array}{l}\text { Age (yr) } \\
\text { and sex }\end{array}$} & \multicolumn{2}{|c|}{ Glucagon dose } & \multirow[t]{2}{*}{ State } & \multicolumn{4}{|c|}{ First exercise period } & \multicolumn{4}{|c|}{ Second exercise period } \\
\hline & & $\mu g / k g$ & $m g$ & & $\begin{array}{l}\text { Heart rate } \\
\text { (beats/min) }\end{array}$ & $\begin{array}{l}\text { Cardiac } \\
\text { index }\end{array}$ & $\begin{array}{l}L V \text { end- } \\
\text { diastolic } \\
\text { pressure } \\
(\mathrm{mmHg})\end{array}$ & $\begin{array}{l}\text { Mean bra- } \\
\text { chial artery } \\
\text { pressure } \\
(\mathrm{mmHg})\end{array}$ & $\begin{array}{l}\text { Heart rate } \\
\text { (beats/min) }\end{array}$ & $\begin{array}{l}\text { Cardiac } \\
\text { index }\end{array}$ & $\begin{array}{l}L V \text { end- } \\
\text { diastolic } \\
\text { pressure } \\
\text { (mmHg) }\end{array}$ & $\begin{array}{l}\text { Mean bra- } \\
\text { chial artery } \\
\text { pressure } \\
(\mathrm{mmHg})\end{array}$ \\
\hline \multirow[t]{3}{*}{10} & $43 M$ & I5 & $I \cdot O$ & 0 & - & - & - & - & 60 & 3.5 & 5 & 86 \\
\hline & & & & I & 64 & $4 \cdot 7$ & 5 & 96 & 68 & 4.5 & 8 & 102 \\
\hline & & & & 2 & 80 & $4 \cdot 8$ & 9 & 92 & 84 & 5.6 & 7 & 98 \\
\hline \multirow[t]{3}{*}{ I I } & $56 \mathrm{M}$ & I5 & $I \cdot O$ & 0 & - & - & - & - & 54 & $3 \cdot 6$ & 14 & 109 \\
\hline & & & & $\mathbf{I}$ & 54 & $3 \cdot 8$ & I5 & I I I & 54 & $3 \cdot 6$ & 14 & IIO \\
\hline & & & & 2 & 66 & $4 \cdot I$ & 21 & 125 & 66 & $5 \cdot 0$ & 16 & I I 8 \\
\hline \multirow[t]{3}{*}{12} & $35 \mathrm{M}$ & 30 & $2 \cdot 1$ & 0 & - & - & 一 & - & 52 & $2 \cdot 7$ & 18 & 97 \\
\hline & & & & $\mathbf{I}$ & 50 & $2 \cdot 8$ & 19 & 98 & 50 & $2 \cdot 6$ & $2 I$ & 98 \\
\hline & & & & 2 & 70 & $4 \cdot 2$ & 22 & 104 & 70 & $4 \cdot 3$ & 20 & 104 \\
\hline \multirow[t]{3}{*}{ I3 } & $42 M$ & 30 & $2 \cdot 0$ & 0 & - & - & - & - & 70 & 4.5 & 3 & 87 \\
\hline & & & & $\mathbf{I}$ & 60 & 3.5 & IO & IOI & 70 & $3 \cdot 8$ & 5 & 90 \\
\hline & & & & 2 & 80 & 4.9 & IO & 96 & 80 & $5 \cdot 1$ & 6 & $9 I$ \\
\hline \multirow[t]{3}{*}{ I4 } & $36 \mathrm{M}$ & 30 & $2 \cdot 3$ & 0 & - & - & - & - & 66 & $3 \cdot 6$ & 17 & 109 \\
\hline & & & & $\mathbf{I}$ & 60 & 3.0 & I 8 & I I I & 64 & $3 \cdot 3$ & I8 & IIO \\
\hline & & & & 2 & 85 & $3 \cdot 8$ & 24 & II7 & 82 & 3.9 & 26 & 112 \\
\hline \multirow[t]{3}{*}{ I5 } & $60 \mathrm{M}$ & 30 & $2 \cdot 5$ & 0 & - & - & - & - & 50 & $2 \cdot 2$ & I9 & 127 \\
\hline & & & & I & 50 & $2 \cdot 0$ & 17 & 108 & 50 & $2 \cdot 5$ & 19 & I 18 \\
\hline & & & & 2 & 60 & $3 \cdot 5$ & 28 & I 27 & 63 & $3 \cdot 2$ & 25 & - \\
\hline \multirow[t]{3}{*}{ I6 } & $43 \mathrm{M}$ & 45 & $3 \cdot 6$ & 0 & - & - & - & - & 69 & $3 \cdot 8$ & 12 & 105 \\
\hline & & & & $\mathbf{I}$ & 72 & $3 \cdot 3$ & 12 & 91 & 72 & $3 \cdot 0$ & IO & IOI \\
\hline & & & & 2 & 90 & $3 \cdot 8$ & 20 & 106 & 90 & $3 \cdot 2$ & 35 & IOI \\
\hline \multirow[t]{3}{*}{${ }_{17}$} & $62 M$ & 45 & $2 \cdot 8$ & 0 & - & - & - & - & 80 & 2.5 & 18 & 133 \\
\hline & & & & I & 84 & $2 \cdot 9$ & I 8 & 146 & 80 & $2 \cdot 9$ & $2 I$ & 149 \\
\hline & & & & 2 & 96 & $2 \cdot 7$ & 31 & I5I & 96 & $2 \cdot 3$ & $3 I$ & I 54 \\
\hline \multirow[t]{3}{*}{ I 8} & $48 \mathrm{M}$ & 45 & $3 \cdot 2$ & 0 & - & - & - & - & 62 & $\mathrm{I} \cdot 7$ & - & 133 \\
\hline & & & & $\mathbf{I}$ & 62 & $2 \cdot 2$ & 34 & 130 & 64 & $I \cdot 8$ & 40 & 148 \\
\hline & & & & 2 & 82 & $2 \cdot 4$ & 43 & 143 & 76 & $2 \cdot 5$ & 39 & 133 \\
\hline \multirow{3}{*}{4 Mean } & & & & 0 & $\overline{ }$ & - & - & - & 62 & $3 \cdot 1$ & I4 & 107 \\
\hline & & & & I & 62 & $3 \cdot 1$ & 16 & I IO & 64 & $3 \cdot 1$ & 17 & I I 4 \\
\hline & & & & 2 & 79 & $3 \cdot 8$ & 23 & I I 8 & 79 & 3.9 & 23 & I I 4 \\
\hline
\end{tabular}

$\star \mathrm{I}=$ immediately before exercise; $2=$ after 3 minutes of exercise; $0=10$ minutes after first exercise period. 


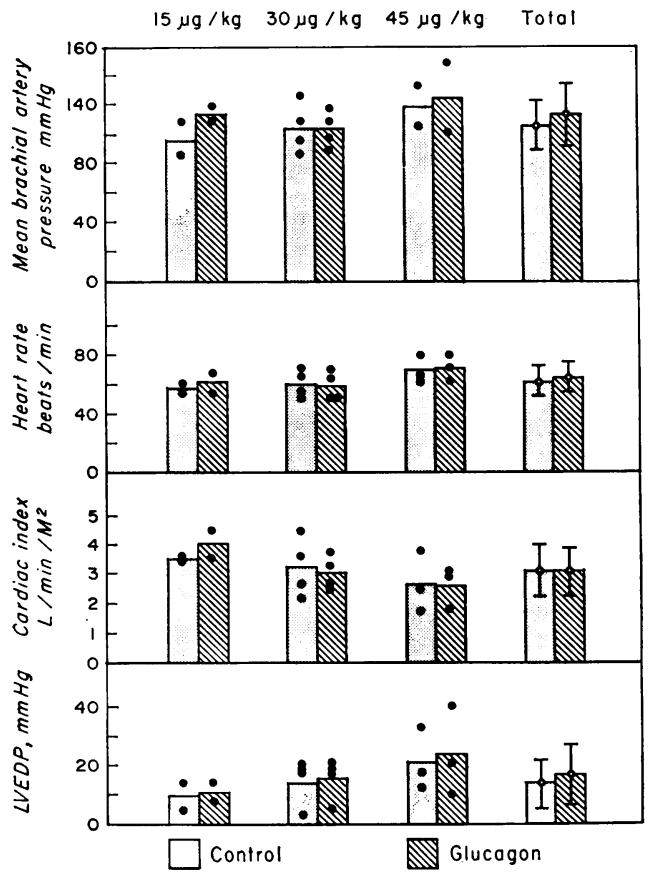

FIG. 5 Haemodynamics before (control) and Io minutes after glucagon administration in patients with coronary heart disease. Effects of different doses on resting haemodynamics. Totals show mean (open circles) and \pm I SD (vertical lines).

loads, and in the erect position. In the present study, in 9 normal subjects, the haemodynamic parameters measured were not significantly different either immediately before or during the final minute of identical periods of mild supine exercise. Such a protocol was useful in evaluating the possible haemodynamic effects of glucagon during exercise in patients with coronary artery disease.

The resting LV end-diastolic pressure was raised in most patients in this study. It was measured while the patient's feet were raised in a bicycle ergometer for 5 minutes, a position associated with a raised LV end-diastolic pressure both in normal man and in patients with coronary artery disease (McCallister et al., 1968). The response to mild supine leg exercise has been proposed as a useful index of left ventricular function in patients with coronary artery disease in the absence of congestive heart failure (Parker, Di Giorgi, and West, 1966). The amount of work performed is small and can be tolerated by most patients. An abnormal increase in LV end-diastolic pressure has been observed during exercise in most patients with coronary artery disease
(McCallister et al., 1968; Parker et al., 1966; Wiener, Dwyer, and Cox, 1968). This is in contrast to the minor changes in LV enddiastolic pressure (range -3 to $+2 \mathrm{mmHg}$ ) in normal subjects so stressed (Ross et al., 1966). This abnormal increase in LV enddiastolic pressure has been reported to be partly related to the extent of the coronary artery disease, as judged from coronary arteriograms (Saltups et al., I97r).

The effects of various pharmacological interventions on exercise haemodynamics in patients with coronary artery disease have been reported. Both nitroglycerin (McCallister et al., 1968; Wiener, Dwyer, and Cox, 1969) and acute digitalization with ouabain (Parker et al., 1969) have resulted in significant decreases in LV end-diastolic pressure during exercise, whereas intravenously administered propranolol has had little effect (Parker, West, and Di Giorgi, 1968; Wiener et al., 1969). The decreased LV end-diastolic pressure after ouabain was believed to reflect an improvement in left ventricular performance (Parker et al., 1969). It was, therefore, of interest to observe whether glucagon might prevent the abnormal increase in LV enddiastolic pressure with exercise in patients with coronary artery disease by its positive inotropic action. With the doses used in the present study, it was not possible to show a positive inotropic action of glucagon on the exercise-induced abnormalities of left ventricular performance in patients with coronary artery disease. This information may be important to clinicians who hope to obtain benefit from the inotropic activity of glucagon in doses well below that which may be associated with induction of nausea and vomiting. In relation to the previously mentioned studies by Gold et al. (1970), which may explain differences in response to glucagon of patients in acute or chronic congestive heart failure, it would also be of interest to know whether chronic myocardial ischaemia without gross congestive heart failure might also alter the capacity of glucagon to stimulate adenyl cyclase.

\section{References}

Burkart, F., Barold, S., and Sowton, E. (1967). Hemodynamic effects of repeated exercise. American fournal of Cardiology, 20, 509.

Epstein, S. E., Robinson, B. F., Kahler, R. L., and Braunwald, E. (1965). Effects of beta-adrenergic blockade on the cardiac response to maximal and submaximal exercise in man. Fournal of Clinical Investigation, 44, 1745 .

Farah, A., and Tuttle, R. (1960). Studies on the pharmacology of glucagon. Fournal of Pharmacology and Experimental Therapeutics, 129, 49. 
Glick, G., Parmley, W. W., Wechsler, A. S., and Sonnenblick, E. H. (1968). Glucagon: its enhancement of cardiac performance in the cat and dog and persistence of its inotropic action despite betareceptor blockade with propranolol. Circulation Research, 22, 789 .

Gold, H. K., Prindle, K. H., Levey, G. S., and Epstein, S. E. (1970). Effects of experimental heart failure on the capacity of glucagon to augment myocardial contractility and activate adenyl cyclase. fournal of Clinical Investigation, 49, 999.

Greenberg, B. H., Tsakiris, A. G., Moffitt, E. A., and Frye, R. L. (1970). The hemodynamic and metabolic effects of glucagon in patients with chronic valvular heart diseases. Mayo Clinic Proceedings, 45, 132.

4 Gregory, J., Mueller, H., Gnoj, J., Ayres, S., Giannelli, S., and Conklin, E. (1969). Effects of glucagon on cardiovascular dynamics and myocardial metabolism in the low output state (abstract). Clinical Research, 17, 243.

Klein, S. W., Morch, J. E., and Mahon, W. A. (1968). Cardiovascular effects of glucagon in man. Canadian Medical Association fournal, 98, I 161 .

Linhart, J. W., Barold, S. S., Cohen, L. S., Hildner, F. J., and Samet, P. (1968). Cardiovascular effects of glucagon in man. American fournal of Cardiology, 22, 706.

McCallister, B. D., Yipintsoi, T., Hallermann, F. J., Wallace, R. B., and Frye, R. L. (1968). Left ventricular performance during mild supine leg exercise in coronary artery disease. Circulation, 37, 922.

Malmborg, R. O. (1965). A clinical and hemodynamic analysis of factors limiting the cardiac performance in patients with coronary heart disease. Acta Medica Scandinavica, Suppl. 426, 5.

Parker, J. O., Di Giorgi, S., and West, R. O. (1966). A hemodynamic study of acute coronary insufficiency precipitated by exercise: with observations on the effect of nitroglycerin. American fournal of Cardiology, 17, 470 .

Parker, J. O., West, R. O., and Di Giorgi, S. (1968). Hemodynamic effects of propranolol in coronary heart disease. American fournal of Cardiology, 21, II.

Parker, J. O., West, R. O., Ledwich, J. R., and Di Giorgi, S. (1969). The effect of acute digitalization on the hemodynamic response to exercise in coronary artery disease. Circulation, 40, 453.

Parmley, W. W., Glick, G., and Sonnenblick, E. H. (1968). Cardiovascular effects of glucagon in man. New England fournal of Medicine, 279, 12.

Regan, T. J., Lehan, P. H., Henneman, D. H., Behar, A., and Hellems, H. K. (1964). Myocardial metabolic and contractile response to glucagon and epinephrine. Fournal of Laboratory and Clinical Medicine, 63, 638.

Ross, J., Jr., Gault, J. H., Mason, D. T., Linhart, J. W., and Braunwald, E. (1966). Left ventricular performance during muscular exercise in patients with and without cardiac dysfunction. Circulation, 34, 597.

Saltups, A., McCallister, B. D., Hallermann, F. J. Wallace, R. B., Smith, R. E., and Frye, R. L. (197I). Left ventricular hemodynamics in patients with coronary artery disease and in normal subjects: correlations with the extent of coronary artery lesions and the electrocardiogram. American fournal of Medicine, 50, 8.

Sonnenblick, E., Parmley, W., and Matloff, J. (1968). Hemodynamic effects of glucagon after prosthetic valve replacement (abstract). Circulation, 38, Suppl. 6,183 .

Widimsky, J., Berglund, E., and Malmberg, R. (1963). Effect of repeated exercise on the lesser circulation. fournal of Applied Physiology, 18, 983.

Wiener, L., Dwyer, E. M., Jr., and Cox, J. W. (1968). Left ventricular hemodynamics in exercise-induced angina pectoris. Circulation, 38, 240.

Wiener, L., Dwyer, E. M., Jr., and Cox, J. W. (1969). Hemodynamic effects of nitroglycerin, propranolol, and their combination in coronary heart disease. Circulation, 39, 623.

Williams, J. F., Jr., Childress, R. H., Chip, J. N., and Border, J. F. (1969). Hemodynamic effects of glucagon in patients with heart disease. Circulation, 39, 38.

Requests for reprints to Dr. R. L. Frye, Mayo Clinic, 200 First Street S.W., Rochester, Minnesota 55901, U.S.A. 